Байкальский государственный университет, г. Иркутск, Российская Федерация

М. Р. Данилова

Байкальский государственный университет, г. Иркутск, Российкая Федерация

\title{
ВЛИЯНИЕ ДЕПОЗИТНОЙ ПОЛИТИКИ НА ФИНАНСОВУЮ УСТОЙЧИВОСТЬ КОММЕРЧЕСКОГО БАНКА
}

\begin{abstract}
АНнОТАЦИЯ. В современных условиях вопрос обеспечения финансовой устойчивости коммерческого банка занимает ключевое место в деятельности любой кредитной организации. На финансовую устойчивость оказывают влияние многочисленные факторы, находящиеся как в сфере деятельности самого коммерческого банка (т. е. внутренние факторы), так и факторы внешней среды. Одним из важнейших факторов, влияющих на финансовую устойчивость кредитной организации, является депозитная политика. Успешное развитие и эффективное функционирование коммерческого банка невозможно обеспечить без детально проработанной и экономически обоснованной депозитной политики, связано это прежде всего с тем, что основная часть ресурсов банка образуется именно в процессе проведения депозитных операций банка, от результативной и грамотно построенной модели организации, от которой, в итоге, зависит устойчивость функционирования любой кредитной организации. В связи с этим вопросы привлечения свободных денежных ресурсов и обеспечения его стабильности посредством эффективной реализации депозитной политики приобретают особую актуальность.

кЛючЕВЫЕ словА. Депозитная политика; кредитная организация; финансовая устойчивость коммерческого банка; стабильность; надежность; ликвидность.

ИНФОРМАЦИЯ О СТАТЬЕ. Дата поступления 11 мая 2016 г.; дата принятия к печати 30 мая 2016 г.; дата онлайн-размещения 22 июля 2016 г.
\end{abstract}

\author{
O. D. Zhilan \\ Baikal State University, \\ Irkutsk, Russian Federation \\ M. R. Danilova \\ Baikal State University, \\ Irkutsk, Russian Federation
}

\section{DEPOSIT POLICY INFLUENCE ON FINANCIAL SUSTAINABILITY OF COMMERCIAL BANKS}

\begin{abstract}
In the current context, the issue of ensuring financial sustainability of commercial banks takes the key place in activity of any credit institution. The financial sustainability is affected by many factors which are involved both in the sphere of commercial bank activity (i.e. internal factors) and external factors. One of the most important factors which influence on financial sustainability of a credit institution is deposit policy. Successful development and effective functioning of the commercial bank can't be provided without properly worked out and economically proven deposit policy. It is connected first of all with the fact that the main part of the bank resources are formed exactly in the process of carrying out deposit operations of the bank, from an effective and properly built model of the organization which eventually influence the sustainability of functioning of any credit institution.In this context, the issues of attracting free monetary resources and providing its sustainability through effective implementation of the deposit policy are becoming specifically topical.
\end{abstract}

KEYWORDS. Deposit policy; credit institution; financial sustainability of commercial banks; stability; reliability; liquidity.

ARTICLE INFO. Received May 11, 2016; accepted May 30, 2016; available online July 22, 2016.

(С) О. Д. Жилан, М.Р.Данилова, 2016

\section{Baikal Research Journal}


Вопросы совершенствования подходов при формировании депозитной политики и ее взаимосвязи с финансовой устойчивостью кредитной организации постоянно обсуждаются на научно-практических конференциях, что находит отражение в исследованиях и статьях таких авторов, как Г. Г. Фетисов [1], Л. В. Татаринова [2; 3], И. М. Стребков [4]; О. Д. Жилан [5-7]; Ю. Б. Бубнова, С. А. Курганский [8] и другие ученые [9-12].

В современной экономической литературе существует множество определений таких понятий, как «надежность», «устойчивость» и «стабильность». Все они признаются синонимами, также не делается различий между особенностью финансовой устойчивости кредитной организации и любого другого предприятия, между стабильностью банковской системы в целом и отдельного банка. В банковском законодательстве РФ используются такие термины, как «стабильность банковской системы» ${ }^{1}$, «устойчивость кредитных организаций» ${ }^{2}$, «финансовая надежность кредитной организации» ${ }^{3}$, однако законодатель не предоставил точного толкования этих терминов.

По мнению В. В. Иванова, надежность характеризуется платежеспособностью, ликвидностью и устойчивостью банка. Под устойчивостью им понимается «стабильность его деятельности в средне- и долгосрочной перспективе; она может быть оценена качеством активов, достаточностью капитала и эффективностью его деятельности" [9, с. 27]. Таким образом автор определяет понятие надежности шире понятия устойчивости и стабильности.

И. М. Стребков, рассуждая об этом явлении, считает, что надежность более всеобъемлющее понятие, чем вероятность выполнения банком целевых установок и обязательств. Устойчивость, по его мнению, является мерой стабильности, а его определение надежности банка имеет кардинальные отличия от понятия устойчивости, в связи с тем, что нацелено на определение вероятности будущих событий $[4$, c. 5].

М. А. Бобрик в своей работе приводит следующее отличие стабильности от устойчивости: «Стабильность - это то, что в том или ином явлении и процессе остается постоянным; устойчивость - это то, что приобретается, изменяется в процессе функционирования в сторону прогресса. Устойчивость дает характеристику процесса не в статическом состоянии, а в динамике. Развитие с позиции устойчивости - всегда позитивное движение, выражающее улучшение, прогресс. Таким образом, устойчивость - это следствие, а стабильность - причина, обуславливающая устойчивость, т.е. устойчивость достигается на основе стабильности» [10, с. 33].

Проанализировав экономическую литературу, автор пришел к выводу о том, что данные понятия (устойчивость, стабильность и надежность) являются не однопорядковыми, а соподчиненными и, следовательно, взаимосвязанными. При этом подчинение строится в следующей последовательности:

- стабильность;

- устойчивость;

- надежность.

Таким образом, надежность может быть определена через призму устойчивости в отдельно взятые временные промежутки при взаимодействии с внешними факторами. Соответственно, саму устойчивость можно охарактеризовать как стабильное финансовое положение, показывающее достаточность активов, эффективное соотношение активов и пассивов, наличие необходимого объема резервов.

${ }^{1}$ О Центральном банке Российской Федерации (Банке России) : федер. закон от 10 июля 2002 г. № 86-ФЗ (ред. от 30 дек. 2015 г.) // СПС «КонсультантПлюс». Ст. 56.

2 Там же. Ст. 62.

${ }^{3}$ О банках и банковской деятельности в Российской Федерации : федер. закон от 2 дек. 1990 г. № 395-1 ( ред. от 20 апр. 2015 г.) // СПС «КонсультантПлюс». Ст. 24.

\section{Baikal Research Journal}


Что касается понятия финансовой устойчивости банка, то существует ряд определений, так, например, Г. Г. Фетисов считает, что финансовая устойчивость коммерческого банка характеризует итоги банковской деятельности, его ресурсы, капитал, доходы и расходы, прибыль и убытки, а также фонды. Некоторые авторы определяют ее как способность банка в современных рыночных условиях оперативно и качественно выполнять свои функции и обязательства по обслуживанию клиентов, а также гарантировать сохранность их вкладов [1, с. 3].

На наш взгляд, основными критериями финансовой устойчивости коммерческого банка являются: ликвидность, качество активов и пассивов и капитальная база банка.

Критерий «ликвидность» определяет возможности банка выполнять свои обязательства перед клиентами. Сам термин «ликвидность» буквально означает легкость реализации, способность быстрого превращения активов в деньги. Конечно, банки, как и остальные звенья финансово-кредитной системы, нуждаются в ликвидных средствах, т. е. в таких активах, которые легко могут быть обращены в денежную наличность с незначительным риском потерь, либо без риска. Действительно, ликвидность считается одним из основных условий финансового благополучия банка. При анализе финансовой устойчивости коммерческого банка важным является всесторонняя и точная оценка ликвидности, которая дает максимальную необходимую информацию о финансовом состоянии банка, перспективах его развития. Данная информация важна как для акционеров и клиентов банка, так и для Центрального банка РФ (ЦБ РФ), который является надзорным органом для всех кредитных организаций. На сегодняшний день ЦБ РФ как финансовый мегарегулятор предписывает соблюдать три норматива ликвидности: мгновенной, текущей и долгосрочной на определенном уровне. Неисполнение данных нормативов может привести к штрафным санкциям со стороны ЦБ РФ, а также введением запрета на осуществление определенных банковских операций, в случае неоднократных нарушений влечет даже отзыв лицензии у банка. Впрочем, в отдельных случаях ЦБ РФ может изменить установленные значения нормативов для банка-нарушителя сроком до шести месяцев.

Критерий «качество активов и пассивов» оценивает возможность обеспечения возврата активов, формирования ресурсной базы, а также воздействие депозитного и кредитного портфеля на финансовую устойчивость банка. Основной задачей оценки устойчивости банка является определение безнадежных, безвозвратных активов. Критерий «качество активов» подразумевает определение величины риска, заложенного в активах, и имеет наибольшее значение для обеспечения финансовой устойчивости банка. Качество пассивов традиционно характеризуется стабильностью и устойчивостью ресурсной базы, стоимостью привлеченных средств, показателями изменений процентных ставок, т. е. те основные элементы, которые непосредственно формируют определенную депозитную политику. Устойчивость ресурсной базы зависит от структуры привлеченных средств, на основании которой определяется портфель активов как по степени риска, так и по срокам. Качество и количество привлеченных средств характеризуют способность банка заинтересовать потенциальных вкладчиков для того, чтобы те смогли доверить им свои денежные средства.

Рассматривая подробнее критерий «капитальная база банка», можно сказать, что он оценивает размер собственного капитала банка с позиции достаточности для удовлетворения интересов своих вкладчиков, а также способности компенсировать понесенные потери. Собственный капитал является основой деятельности каждого банка и одним из главных источников ресурсной базы, который также выступает неким гарантом успешного функционирования банка, призванный защищать и поддерживать его финансовую устойчивость и надежность, вызывая доверие со стороны клиентов. Отсюда следует вывод, что поддержание достаточного уровня капитала и есть одно из основных условий стабильности банковской системы.

\section{Baikal Research Journal}

электронный научный журнал Байкальского государственного университета 
От размера собственного капитала, пассивов банка, качества и количества привлеченных средств во многом зависит размер кредитных ресурсов банка, в конечном счете, размер получаемой банком прибыли, его финансовая устойчивость и надежность [5, с. 25].

Объем и структура всех привлеченных ресурсов, качество депозитной базы существенно влияют на уровень финансовой устойчивости банка:

- от объема привлеченных ресурсов зависит проведение активных операций, которые приносят доход, а также укрепляют позиции банка среди его конкурентов;

- стоимость привлеченных средств влияет на понесенные банком расходы, а также уровень прибыли;

- соответствие структуры привлеченных ресурсов структуре активов банка определяет ликвидность, т. е. способность банка отвечать по своим обязательствам перед клиентами.

Из значимости объема и качества привлеченных ресурсов вытекают следующие критерии их оценки:

- влияние ресурсной базы на ликвидность банка;

- роль структуры ресурсов в увеличении прибыли;

- значение ресурсной базы в укреплении позиции банка среди конкурентов.

Большая часть привлеченных ресурсов в основном формируется в процессе осуществления депозитных операций банка, от эффективного и правильного совершения которых зависит успешная деятельность каждой кредитной организации, что, таким образом, является предпосылкой к разработке депозитной политики. Роль депозитной политики коммерческого банка отражается в обеспечении рентабельности и ликвидности, создании условий стабильности, устойчивости и надежности, а также деятельности, соответствующих потребностям клиентов [6, с. 21].

Среди множества различных факторов, влияющих на финансовую устойчивость банка и непосредственно взаимосвязанных с депозитной политикой, мы выделяем следующие:

1. Поддержание и сохранение оптимального уровня ликвидности, как уже неоднократно отмечалось ранее, является важнейшим условием достижения устойчивости коммерческого банка. Депозитная политика в деятельностном аспекте представляет собой комплекс мероприятий, целью которых является обеспечение ликвидности ресурсов. Основное внимание уделяется качеству привлеченных средств клиентов, так как наличие устойчивой части в депозитах повышает ликвидность банка. Устойчивые депозиты - это и есть та самая часть депозитов, которая не покидает банк, они могут быть среди расчетных и текущих счетов, а также срочных и сберегательных вкладов. Однако как показывает практика, устойчивая часть депозитов выше всего среди вкладов до востребования. Есть также изменчивая часть, к которой причисляют депозиты, чувствительные к изменениям процентных ставок, обычно их относят к срочным и сберегательным вкладам.

2. Выбор стратегии и приоритетов развития, прогнозирование финансовых потребностей своей деятельности - ключевые моменты для банка. Важнейшей чертой содержания устойчивости является соответствие стратегии банка объективным характеристикам той фактической реальности, в которой ему приходится работать, а также соответствие текущих параметров деятельности банка его собственным стратегическим целям. С позиции рассмотрения в сущностном аспекте под депозитной политикой понимается стратегия и тактика банка в части организации депозитного процесса. Обоснование выбора определенной стратегии и тактики, его приоритетов развития позволяют банкам более продуманно, с определенным ориентиром на будущее выстраивать свою текущую деятельность, а также реализовывать конкретную депозитную политику.

\section{Baikal Research Journal}


3. Существенным фактором создания финансовой устойчивости является формирование доверия к банкам. Банки, пользующиеся доверием экономических субъектов, успешнее привлекают депозиты физических и юридических лиц. Чем выше «преданность и доверие» к банку, тем ниже вероятность досрочного изъятия средств, во всяком случае до тех пор, пока банк финансово устойчив. Именно из-за отсутствия доверия часто подрывается ликвидность, снижается финансовая устойчивость банка. Неслучайно в западной литературе современный финансовый кризис описывают как кризис доверия. Современное российское общество пока не разработало конкретной теории доверия в банковской сфере, не научилось признавать, что снижение доверия является предвестником кризисных явлений. Между тем к данному фактору следует отнестись с особенной внимательностью, чтобы избежать неоправданных потерь.

Таким образом, подводя итоги, можно сделать основные выводы:

1. Банк признается финансово-устойчивым, когда его деятельность показывает положительную динамику, при этом устойчивость достигается в случае непрерывного прогрессивного процесса, несмотря на негативную экономическую ситуацию или мировой финансовый кризис.

2. Финансовая устойчивость коммерческого банка - это такое соотношение источников привлечения денежных средств и их размещение, при котором коммерческий банк сможет гарантировать выполнение своих обязательств перед клиентами, а также имеет возможность активно и успешно развиваться, приносить прибыль и финансировать собственную деятельность в долгосрочной перспективе.

3. Формирование и реализация депозитной политики тесно взаимосвязаны с финансовой устойчивостью коммерческого банка, точнее сказать, оказывают непосредственное влияние на способность банка формировать и использовать финансовые ресурсы, обеспечивать бесперебойный процесс своей деятельности.

\section{Список использованной литературы}

1. Фетисов Г. Г. Устойчивость банковской системы и методология ее оценки : автореф. дис. ... д-ра экон. наук : 08.00.10 / Г. Г. Фетисов. - М., 2003. - 16 с.

2. Татаринова Л. В. Методические подходы к оценке финансовой устойчивости коммерческого банка / Л. В. Татаринова. - Иркутск : Изд-во БГУЭП, 2013. - 132 с.

3. Татаринова Л. В. Банковское обслуживание частных клиентов / Л. В. Татаринова // Развитие финансово-кредитной системы региона : сб. науч. тр. / отв. ред. С. Ю. Куницына. Иркутск : Изд-во БГУЭП, 2011. - С. 104-110.

4. Стребков И. М. Надежность и устойчивость коммерческого банка в конкурентной среде : автореф. дис. ... канд. экон. наук : 08.00.10 / И. М. Стребков. - М., 1999. - 23 с.

5. Жилан О. Д. Депозитная политика коммерческого банка / О. Д. Жилан. - Иркутск : Изд-во БГУЭП, 2009. - 212 с.

6. Жилан О. Д. Ликвидность коммерческого банка : учеб. пособие / О. Д. Жилан. - Иркутск : Изд-во БГУЭП, 2013. - 107 с.

7. Жилан О. Д. Деньги, кредит, банки : в 2 ч. : учеб. пособие / О. Д. Жилан. - Иркутск : Изд-во БГУЭП, 2014. - 118 с.

8. Курганский С. А. Фундаментальные показатели экономики : монография / С. А. Курганский. - Иркутск : Изд-во БГУЭП, 2009. - 116 с.

9. Иванов В. В. Анализ надежности банка : практ. пособие / В. В. Иванов. - М. : Рус. дел. лит., 1996. - $320 \mathrm{c}$.

10. Бобрик М. А. Финансовая устойчивость коммерческого банка / М. А. Бобрик // Банковское дело. - 2011. - № 8. - С. 32-35.

11. Варламова С. Б. Принципиальная модель бизнес-стратегии обеспечения финансовой устойчивости как фактора конкурентоспособности коммерческого банка / С. Б. Варламова // Банковские услуги. -2014 . - № 2. - С. 20-24.

12. Готовчиков И. Ф. Технологии оценки финансового состояния и финансовой устойчивости российских банков / И. Ф. Готовчиков // Банковские технологии. - 2007. — № 3. - C. 40-48.

\section{Baikal Research Journal}




\section{References}

1. Fetisov G. G. Ustoichivost' bankovskoi sistemy i metodologiya ee otsenki. Avtoref. Dokt. Diss. [Sustainability of banking system and methodology of its assessment. Doct. Diss. Thesis]. Moscow, 2003. $16 \mathrm{p}$.

2. Tatarinova L. V. Metodicheskie podkhody $k$ otsenke finansovoi ustoichivosti kommercheskogo banka [Methodical approaches to assessing financial sustainability of the commercial bank]. Irkutsk, Baikal State University of Economics and Law Publ., 2013. 132 p.

3. Tatarinova L. V. Banking servicing of private clients. In In Kunitsyna S. Yu. (ed.). Razvitie finansovo-kreditnoi sistemy regiona [Development of regional finance and credit system]. Irkutsk, Baikal State University of Economics and Law Publ., 2011, pp. 104-110. (In Russian).

4. Strebkov I. M. Nadezhnost' i ustoichivost' kommercheskogo banka v konkurentnoi srede. Avtoref. Kand. Diss. [Reliability and sustainability of the commercial bank in competitive environment. Cand. Diss. Thesis]. Moscow, 1999. 23 p.

5. Zhilan O. D. Depozitnaya politika kommercheskogo banka [Deposit-taking policy of commercial bank]. Irkutsk, Baikal State University of Economics and Law Publ., 212 p.

6. Zhilan O. D. Likvidnost' kommercheskogo banka [Commercial bank liquidity]. Irkutsk, Baikal State University Economics and Law Publ., 2013.107 p.

7. Zhilan O. D. Den'gi, kredit, banki [Money, credit, banks]. Irkutsk, Baikal State University of Economics and Law Publ., 2014. 118 p.

8. Kurgansky S. A. Fundamental'nye pokazateli ekonomiki [Fundamental economic indicators]. Irkutsk, Baikal State University of Economics and Law Publ., 2009. 116 p.

9. Ivanov V. V. Analiz nadezhnosti banka [Analysis of bank reliability]. Moscow, Russkaya delovaya literatura Publ., 1996. 320 p.

10. Bobrik M. A. Financial sustainability of the commercial bank. Bankovskoe delo = Banking, 2011, no. 8, pp. 32-35. (In Russian).

11. Varlamova S. B. A principle model of business strategyfor providing financial sustainability as a factor of commercial banks' competitiveness. Bankovskie uslugi= Banking services, 2014, no. 2, pp. 20-24. (In Russian).

12. Gotovchikov I. F. Technologies of assessing financial state and financial sustainability of Russian banks. Bankovskie tekhnologii = Banking Technology, 2007, no. 3, pp. 40-48. (In Russian).

\section{Информация об авторах}

Жилан Оксана Длитриевна - кандидат экономических наук, доцент, кафедра банковского дела и ценных бумаг, Байкальский государственный университет, 664003, г. Иркутск, ул. Ленина, 11, e-mail: gilan2004@mail.ru.

Данилова Мария Ролановна - магистрант, кафедра банковского дела и ценных бумаг, Байкальский государственный университет, 664003, г. Иркутск, ул. Ленина, 11, e-mail: maria_danilova91@mail.ru.

\section{Authors}

Oksana D. Zhilan - PhD in Economics, Associate Professor, Chair of Banking and Securities, Baikal State University, 11 Lenin St., 664003, Irkutsk, Russian Federation; e-mail: gilan2004@mail.ru.

Mariya R. Danilova - Master Degree Student, Chair of Banking and Securities, Baikal State University, 11 Lenin St., 664003, Irkutsk, Russian Federation; e-mail: maria_danilova91@mail.ru.

\section{Библиографическое описание статьи}

Жилан О. Д. Влияние депозитной политики на финансовую устойчивость коммерческого банка / О. Д. Жилан, М. Р. Данилова // Baikal Research Journal. - 2016. — Т. 7, № 4. — DOI : 10.17150/2411-6262.2016.7(4).4.

\section{Reference to article}

Zhilan O. D., Danilova M. R. Deposit policy influence on financial sustainability of commercial banks. Baikal Research Journal, 2016, vol. 7, no. 4. DOI : 10.17150/2411-6262.2016.7(4).4. (In Russian).

\section{Baikal Research Journal}

